\title{
Towards a smart automated surface irrigation management in rice-growing areas in Italy
}

\author{
Daniele Masseroni, ${ }^{1}$ Jasim Uddin, ${ }^{2}$ Reece Tyrrell, ${ }^{3}$ Iven Mareels, ${ }^{4}$ Claudio Gandolfi, ${ }^{1}$ Arianna Facchi ${ }^{1}$ \\ ${ }^{1}$ Department of Agricultural and Environmental Sciences, University of Milano, Milano, Italy; ${ }^{2}$ National Centre for \\ Engineering in Agriculture, University of Southern Queensland, Toowoomba, QLD, Australia; ${ }^{3}$ Rubicon Water, \\ Shepparton, VIC, Australia; ${ }^{4}$ Melbourne School of Engineering, University of Melbourne, VIC, Australia
}

\begin{abstract}
Italy is the leading rice producer in Europe, accounting for more than half of the total high-quality production of this crop. Rice is traditionally grown in fields that remain flooded starting with crop establishment until close to harvest, and this traditional irrigation technique (i.e., continuous submergence) is recognised as an important water resource sink (almost $40 \%$ of the irrigation water available worldwide is used for paddy areas). Meanwhile, the water management in rice areas requires a high level of labour because it is based on maintaining a predetermined water height in
\end{abstract}

Correspondence: Daniele Masseroni, Department of Agricultural and Environmental Sciences (DiSAA), University of Milano, via Celoria 2, 20133 Milano, Italy.

Tel.: +39.02503.16903 - Fax: +39.02503.16900.

E-mail: daniele.masseroni@unimi.it

Key words: Rice field irrigation management; automatic and remote controlled gate; real-time optimisation.

Acknowledgements: we wish to thank Dr. David Aughton of Rubicon Water and its delegate for Italy, Dr. Tullio Zanotti, for designing and supplying the installed technology. We are grateful to the Est Sesia Irrigation Association and, in particular, to Dr. Alberto Lasagna and Dr. Alessandro Spataro for realising the concrete structures. We thank Dr. Paolo Carnevale (owner of the Cerino farm) for hosting the experiments. Finally, we thank the anonymous reviewer for his/her valuable suggestions and comments.

Funding: this work is part of the WATPAD (WATer impacts of PADdy environment) project, aimed at quantifying water balance terms in ricegrowing areas at different spatial scales. We thank Fondazione Cariplo for funding the project (Grant Number 2014-1260), the Ente Nazionale Risi (ENR) and the University of Eastern Piedmont (UPO) involved in the project together with the University of Milano.

Received for publication: 5 August 2016.

Accepted for publication: 30 September 2016.

CCopyright D. Masseroni et al., 2017

Licensee PAGEPress, Italy

Journal of Agricultural Engineering 2017; XLVIII:585

doi:10.4081/jae.2017.585

This article is distributed under the terms of the Creative Commons Attribution Noncommercial License (by-nc 4.0) which permits any noncommercial use, distribution, and reproduction in any medium, provided the original author(s) and source are credited. paddy fields and because the regulation of input and output flow is typically operated manually by the farmer. This study reveals the hardware and software characteristics of an automated and remote controlled technology tested for the first time in a rice farm near Pavia (Italy), during the 2016 growing season, aiming at a more efficient and less burdensome irrigation management system for rice fields. A water level sensor in the field provides the data required to govern the inflow regulation gate in real-time, according to the precise time to cut off the flow rate. Using a dedicated web page, the farmer can control flows, volumes and water levels in the fields by operating directly on the gate if necessary or setting the irrigation program according to his agronomic practices.

\section{Introduction}

Various attempts to develop and apply automated surface irrigation systems have been reported in the literature (Niblack and Sanchez, 2008; Dassanayake et al., 2010; Shahidian and Serralheiro, 2012). However, despite a demonstrated potential to save labour and water, none of these systems has been commercially adopted due to their disadvantages, particularly, their complexity and cost.

Automated systems for bay irrigation, such as FarmConnect $\AA$ (Rubicon Water, 2013) and Aquator (G\&M Poly Irrigation, 2013), are commercially available in Australia. Adoption of these systems is growing, particularly in northern Victoria, in response to the combined influences of a modernised and automated supply system, growers' access to higher and more consistent flow rates, increasing labour costs, and government incentives for on-farm improvements. To date, these systems have been applied to furrow irrigation, with suitable infrastructure to deliver water to the furrows in a controlled and uniform manner. Along with these developments, the cotton industry has been funding the development of a real-time optimisation system for furrow irrigation (Khatri and Smith, 2006, 2007; Koech et al., 2014). Preliminary trials by Koech et al. (2014) have shown that these systems are effective in improving application efficiency above the efficiencies routinely achieved by the growers. There are no reports in the literature on the application of these automated systems for the irrigation of rice fields.

The FarmConnect ${ }^{\circledR}$ system is a group of hardware products (e.g., gates, valves, water level sensors, soil moisture probes, flow meters, rain gauges) and software products used to improve surface irrigation, providing a remote and automated irrigation management system to reduce water use and labour while improving crop quality and quantity. The products interact with each other to provide advanced control and feedback, and they enable schedul- 
ing of irrigation actions. A web interface facilitates access to onfarm data in real time and stores historical data for reference. A detailed alarm scheme notifies users of potential irrigation problems as, or even before, they occur. In addition, complex irrigation schemes can be established via the web interface and downloaded remotely into the system, enabling time-based or event-driven irrigation routines on multiple devices.

The automatic and remote controlled FarmConnect ${ }^{\circledR}$ systems are widely adopted on farms in the southern part of Australia (mainly in the state of Victoria) and in California (United States of America) where gravity-fed surface irrigation methods are currently adopted to irrigate large portions of cultivated areas (Gillies et $a l ., 2010)$. Different case studies in which these systems are adopted for wheat, barley, faba bean, canola and maize crops demonstrated that the application of automatic bay-drive systems leads to a reduction of the time spent by the farmer for irrigation (Koech et $a l ., 2014)$ and to an increase in water application efficiency (Smith et al., 2016). In these areas, farmers managed properties ranging from 200-800 hectares, with single fields characterised by a surface of approximately 8-10 hectares. Because of the large field size, these automatic systems are known as bay-drive systems, and in these case study contexts, they must be able to deliver discharges of more than one cubic meter per second to the field. In cases with a large field size and the absence of these systems, much of the farmers' work is dedicated to irrigating each bay, requiring several hours for each of them. Interviews with farmers showed that they constantly had to stop other farm chores to close and open the bay gates. These gates are habitually closed late relative to the optimal cut-off time, leading to a water wastage of approximately $20 \%$ compared with the real crop requirements of each irrigation event (Gillies and Smith, 2015). The introduction of well-designed and well-managed gravity-fed surface irrigation systems using bay-drive automatic and remote controlled gates could potentially deliver application efficiencies up to $90 \%$ (Smith et al., 2016). For example, an extensive number of furrow irrigation evaluations in the Australian sugar and cotton industries during the 1990s (Raine and Bakker, 1996; Smith et al., 2005) found application efficiencies for individual furrow irrigations averaging approximately $50 \%$ and ranging from 10 to $90 \%$. In cotton production, an increase in the furrow inflow rates of $6 \mathrm{~L} / \mathrm{s}$ combined with a reduction in the irrigation duration (time to cut-off) enabled attaining an average application efficiency of approximately 75\% (Smith et al., 2005). The analysis of the cotton industry irrigation water consumption showed that over a 16-year period, the wide adoption of bay-drive automatic irrigation systems allowed a water savings of approximately $28.510^{6} \mathrm{~m}^{3} /$ year, which contributed to an industry improvement in water use efficiency of 10\% (BDA Group, 2007).

A similar situation occurred for the dairy industry in the Goulburn-Murray Irrigation District (GMID) in northern Victoria, Australia. A study by the Cooperative Research Centre for Irrigation Futures (Smith et al., 2009; Gillies et al., 2010) demonstrated that significant gains in application efficiency (approximately $20 \%$ ) can be reached in the bay irrigation of pasture and fodder crops simply by doubling the flow rates (to at least $0.210^{6}$ $\mathrm{m}^{3} /$ day/m width) and reducing the irrigation durations. Generally, in these cases, the type of flow control was dependent on the soil water content, which was monitored using multi-level sensors placed within each field. The continuous monitoring of the soil water content compared with the crop-specific water stress threshold provided a framework for when to irrigate and how much water to apply.

In this study, a commercial system for the smart automation for flooded irrigation of rice fields is described. The system combines real-time optimisation with a commercially available automation system. Prototype testing of a new design in-field infrastructure and real-time optimisation is also presented.

\section{Rice irrigation features in the Italian agricultural context}

Rice is an important crop from a nutrition perspective since it is the primary food in the diet of more than half the world's population. Approximately $90 \%$ of world rice production is grown in Asia, while the quantities produced in Europe are relatively limited (approximately 3 million tons). Italy, with more than half of the total European rice production, is the first producer of the old continent (ISTAT, 2009; EUROSTAT, 2013). The most important ricegrowing area is the portion of the Padana plain located to the east of Ticino River, straddling the regions of Lombardy and Piedmont in northern Italy (more than 200,000 hectares, $92 \%$ of the Italian rice surface; National Rice Centre, 2015). Although the main objective of the rice farms is productive, areas in which the prevailing crop is rice create a peculiar agro-ecosystem characterised by the presence of water in the fields for several months each year (Leibundgut and Kohn, 2014). This extensive water presence endows these areas with significant landscape and natural heritage values, ranging from the preservation of traditional rural landscapes to the safeguarding of different animal and plant species typical of wetland areas (Cesari de Maria et al., 2016). The prolonged presence and circulation of water due to continuous flooding of fields from wet-sowing until close to harvest represent a distinguishing feature of these rice areas, some of which have also been included in the European ecological network NATURA 2000 and on the official list of the European Special Protected Areas (Habitat Directive, 92/43/EEC; European Commission, 1992) (Chiaradia et al., 2013). However, the traditional irrigation technique, which still dominates in most areas (for example, in $85 \%$ of the northern Italy river basin area), is characterised by very low irrigation efficiencies and a high level of labour requirements performed by practitioners (named in Italian Acquaioli), combining rich hands-on experience and local traditional knowledge. Although there are no accurate measurements related to the time that farmers spend for irrigation management of their fields, it may be estimated that a significant fraction of the working day during the agricultural season is dedicated to the control and adjustment of the gates to maintain the correct levels of water inside the paddy fields. This fraction of the day can vary considerably depending on the extension of the cultivated area, the growing period and the fragmentation of the rice-growing property, but it can be considered approximately $40 \%$ on average (Sekozawa, 2010). This value implies a significant effect on the fixed costs of individual companies, primarily for the assumption of seasonal workers' time that is dedicated full-time or part-time to irrigation management.

Another important factor to consider is that the current rice cultivation methods differ greatly from the permanent submersion method used in the past (Russo and Callegarin, 2007). Moreover, in the last decade, there was an impetus to find increasingly sophisticated agronomic techniques to improve and optimise soil tillage and crop management. An example of these techniques is called pin-point (LSU AgCentre, 2014), which consists of repeated stages of submergence alternating with dry periods that are performed immediately after sowing to allow a good rooting of the seedlings while avoiding soil hardening and reducing algal proliferation. During the remaining growing season, the plots can be dried or treated with continuous changes in the water level to increase the effectiveness of herbicide and fungicide treatments that reduce the occurrence of problems such as rice water weevil and bacterial rot (National Rice Centre, 2015). It can be easily imagined that the 
guidelines and warnings (currently tested in specialised research centres such as the National Rice Centre) would not be entirely applicable by individual rice growers without a significant quantity of workers to control each plot. Therefore, there is a current need for an automated and remote controlled irrigation management system aimed at facilitating the tasks of rice growers to reduce the management costs and to permit the application of the most advanced agronomic techniques necessary to obtain high-quality products with low environmental impacts.

\section{Materials and methods}

\section{Description of the smart system for rice field trials}

\section{The experimental field}

The first prototype of a smart FarmConnect ${ }^{\circledR}$ system for flood irrigation of rice is being tested at the Cerino farm $\left(45^{\circ} 08^{\prime} \mathrm{N}\right.$ $8^{\circ} 44^{\prime} \mathrm{E}, 94 \mathrm{~m}$ a.s.1.) in the province of Pavia, Italy (Figure 1). The farm is located in the Est-Sesia irrigation district, which is approximately $45 \mathrm{~km}$ southwest of the city of Milano. The site is characterised by nearly homogeneous soils and an average slope of approximately $1 \%$. The local climate is humid subtropical (Cfa) according to the Köppen climate classification (Köppen, 1936), with an average temperature of $20^{\circ} \mathrm{C}$ and a cumulative rainfall depth of approximately $360 \mathrm{~mm}$ during the agricultural season (average values for April-September of 1993-2013). The soil type is a mix of $70 \%$ of Aquultic Haplustalfs Coarse loamy, Mixed,
Superactive, Mesic and 30\% of Typic Endoaquepts Coarse loamy, Mixed, Superactive, Nonacid, Mesic (USDA, 1975; ERSAL, 1993), with a high percentage of sand (Cesari de Maria et al., 2016). According to the ROSETTA pedo-transfer functions (Schaap et al., 2001), the saturated hydraulic conductivities are approximately $1 \mathrm{~cm} \mathrm{~d}^{-1}$ along the soil profile up to the plowing sole (at a depth of $55 \mathrm{~cm}$ ). The groundwater table is shallow, with the groundwater depth ranging from less than one meter during the summer to approximately two meters during the winter. A canal, named Roggia Raina, fed by a spring, provides irrigation to the Cerino farm and guarantees a constant supply of approximately 2 $\mathrm{m}^{3} \mathrm{~s}^{-1}$ throughout the agricultural season. The main concrete diversion canal that supplies water to the farm fields is connected to Roggia Raina by a sluice gate whose maximum diversion capacity is approximately $800 \mathrm{~L} / \mathrm{s}$. This gate is manually governed according to the farmers' needs. Rice cultivation is currently performed under continuous submergence, with an irrigation depth of approximately $150 \mathrm{~mm}$ in the field and an inflow rate in each field ranging from $50 \mathrm{~L} / \mathrm{s}$ to $100 \mathrm{~L} / \mathrm{s}$.

The Cerino farm property is approximately 100 hectares, subdivided into 20 fields with an average of 5 hectares. This high level of field fragmentation is typical of the Italian rural areas, which are also characterised by extensive networks of irrigation canals supplying water to each field and collecting the drained water. Irrigation canals are often indiscriminate since they are often used as drainage canals in which the drained water is mixed with irrigation water and delivered to downstream areas. At the farm level, water is diverted from the main farm canal through a series of sluices that the farmer opens and closes in sequence to obtain the

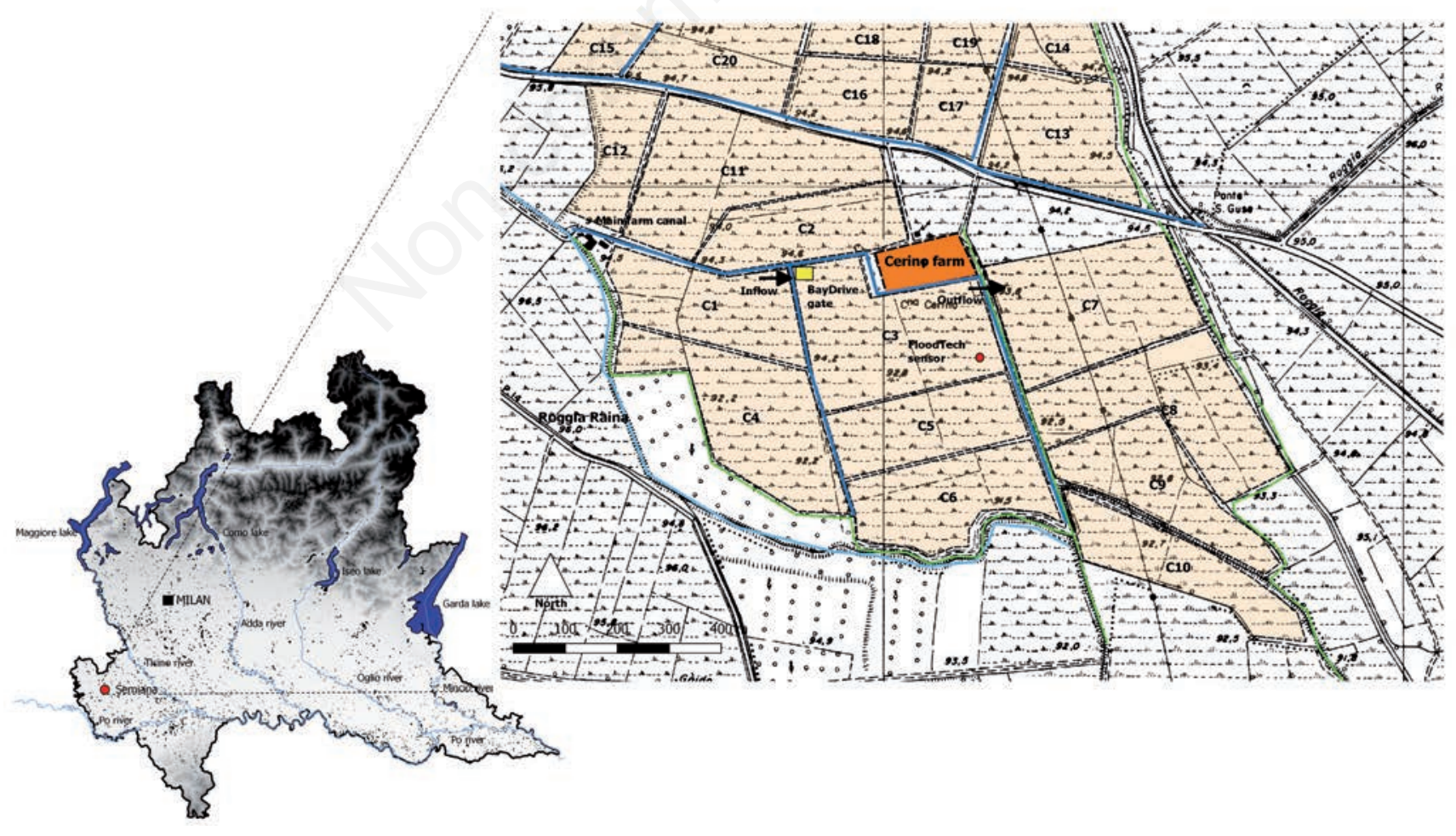

Figure 1. Cerino farm with bay-drive gate and water level sensor positions. 
optimal field inflow, which is evaluated according to his practical experience. Therefore, automatic and remote controlled bay-drive gates could result in better irrigation management that is less timeconsuming and more controlled and reproducible.

\section{Farm Connect ${ }^{\circledR}$ hardware description}

The FarmConnect ${ }^{\circledR}$ system for rice is based on an automated gate (BayDrive - Rubicon Water AU) governed by an ultrasonic water level sensor placed in the field (FloodTech Sensor - Rubicon Water AU). In Figure 2, the device design and its installation in the field are shown. The FloodTech Sensor continuously monitors the water level at the end of the paddy field and sends the information to a master control system (FarmConnect ${ }^{\circledR}$ Gateway - Rubicon Water AU) that provides instructions to open or close the gate as required to maintain a predetermined water level in the field. Upstream of the gate, a time-of-flight flow meter (Sonaray FlumeMeter - Rubicon Water AU) was added for the continuous monitoring of irrigation water discharges.

The BayDrive is a remotely operated field input gate actuator. It has been retrofitted to the case study paddy field by mounting it in a concrete emplacement with a rubber flap gate for optimal flow regulation. The local control of the gate can be performed via a toggle switch or remotely via FarmConnect ${ }^{\circledR}$ software (Rubicon Water AU). The BayDrive arms are driven by a CableDrive ${ }^{\mathrm{TM}}$ system designed for high duty cycle operation. CableDrive provides positive drive in both the raise and lower directions, enabling the gate to open and close under high flows in a high-pressure environment. The CableDrive mechanism, consisting of a stainless steel wire rope and a cable drum, permits opening and closing the gate during all operating phases. The gate motor has a $12 \mathrm{~V}$ DC power supply powered by a single $20 \mathrm{~W}$ solar panel and one $12 \mathrm{~V}$ sealed gel lead-acid battery capable of guaranteeing 5 days of operation without solar power and with an approximate lifespan of 5 years, at which time the battery should be simply replaced with a new one. The power and control technologies are housed in the radio unit box. The communication protocol is based on ZigBee standards with a radio frequency of $2.4 \mathrm{GHz}$ and a transmission range of approximately $1 \mathrm{~km}$. The BayDrive is also equipped with emergency controls for manual opening of the gates in case of a blackout or system failure.

The FloodTech sensor uses an ultrasonic water level sensor to measure the rise of water in the field in a vertical tube whose open base is located in a chamber or cup that is installed below the ground surface level. This sensor can measure levels at up to a 70$\mathrm{cm}$ distance from the ground surface with a maximum error of $+/$ $0.05 \mathrm{~mm}$. The FloodTech sensor is also equipped with a $12 \mathrm{~V}$ battery, $20 \mathrm{~W}$ solar panel and the ZigBee communication protocol.

The Sonaray FlumeMeter measures both the height and velocity of the water inside the concrete canal to determine the flow rate; hence volume integrating the flow rates during each irrigation event. This meter consists of a rectangular box with 32 individual acoustic sensors arranged in four cartridges across eight planes of measurement. The flow meter can measure with an accuracy of $+/$ $2.5 \%$ for velocities greater than $25 \mathrm{~mm} / \mathrm{s}$. The water level within the FlumeMeter is measured with an accuracy of $0.5 \mathrm{~mm}$ and a resolution of $0.1 \mathrm{~mm}$. The Sonaray FlumeMeter is equipped with the ZigBee communication protocol powered by a $12 \mathrm{~V}$ DC battery and a $10 \mathrm{~W}$ solar panel, allowing measurements to be sent to the mother station.

Finally, the FarmConnect ${ }^{\circledR}$ Gateway provides an interface between cellular networks and BayDrive, FloodTech and Sonaray devices. This interface uses the Telstra NextG protocol to routinely upload the data [through a global system for mobile (GSM) connection] to a Host Server for remote monitoring and control.

Within this context, the FarmConnect ${ }^{\circledR}$ system is characterised by five distinct advantages: i) automated control with feedback the gate will move automatically at a set time or due to specific events. Data from the water level sensor are used to trigger the gate
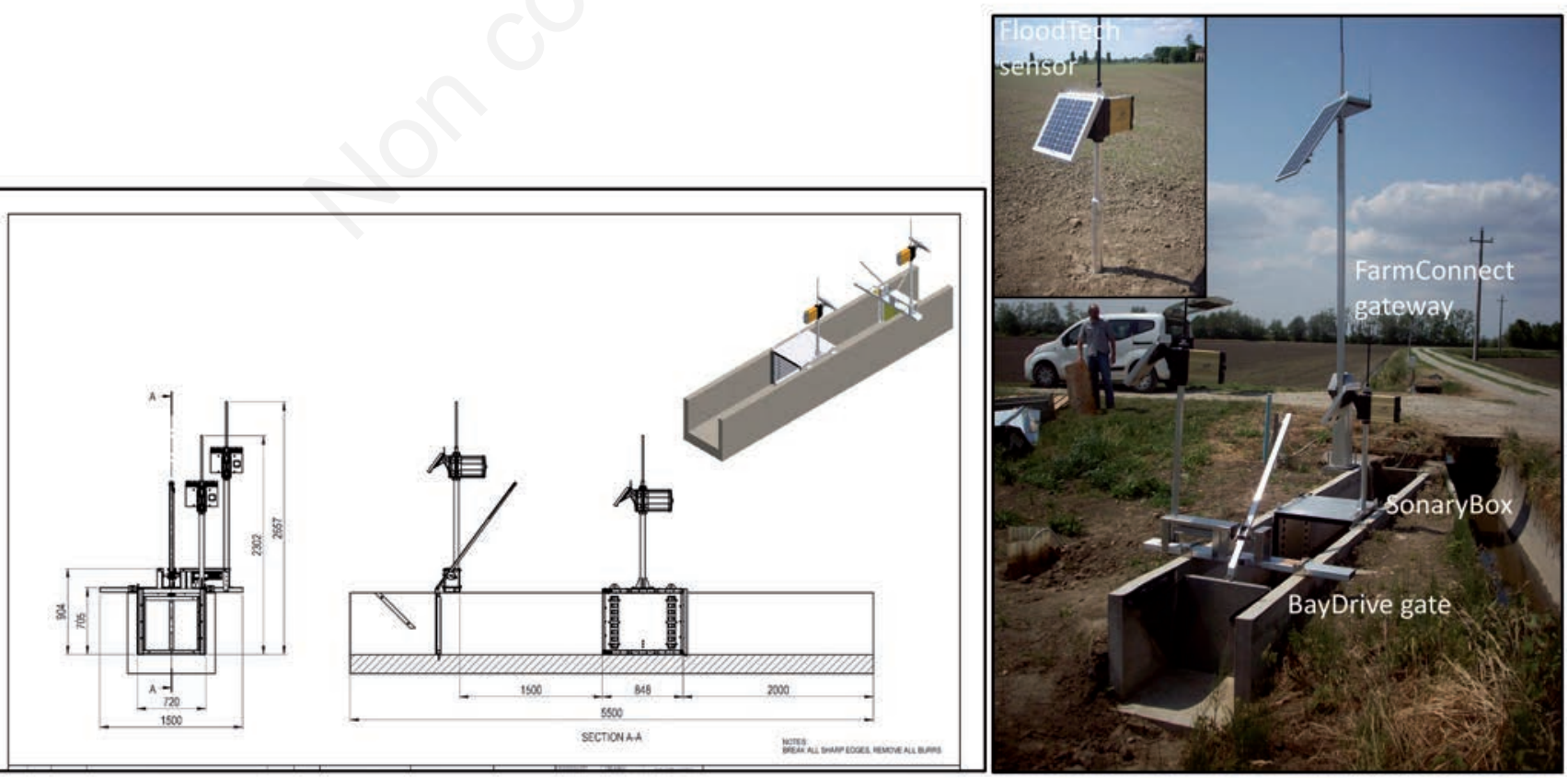

Figure 2. Design and installation of the bay-drive gate and water level sensor in the field. 
to open or close as required. Complex irrigation scheduling can be established via the web interface and left to run with no need for on-site user interaction; ii) real-time optimisation - continuous exchange of information between the feedback devices and control gates, meaning that irrigation events occur exactly when required; iii) intelligent alarming - a range of alarms can be configured and delivered as text messages or email to alert users when specific constraints occur; iv) remote access and data logging - historical data from all components within the system are available via the web interface and can be used to drive important decisions. These data are protected by a password with multiple levels of user permissions and can be accessed anywhere with Internet access, including on smartphones; v) self-powered - each device is equipped with a battery and a solar panel, and communication between devices is via a radio network. Communication between the master device and the server is via GSM.

The main project changes in this rice experiment are related to the small dimensions of the experimental gate. The dimensions of the BayDrive in the case study are only $720-\mathrm{mm}$ wide and $620-\mathrm{mm}$ high, whereas traditional gates are generally two or three times larger (Koech et al., 2014). This specific requirement led to the necessity of developing an ad hoc gate, whose installation should also guarantee the preservation of the structural hydraulic knots of the farm. Currently, at the Cerino farm, the inflow at each field passes through a concrete circular opening (with a $40-\mathrm{cm}$ diameter) with a manual gate governed by the farmer. These hydraulic structures have an ancient origin and are considered an integral part of farm history. Although the simplest solution appeared to be replacing these hydraulic elements with the BayDrive emplacement, it was preferable to construct a concrete canal directly behind the circular opening, with a rectangular section of the same dimensions as those of the BayDrive gate. This canal is five meters long to allow insertion of the BayDrive and the Sonary FlumeMeter. The particular length of the rectangular concrete canal will guarantee the regularisation of the turbulent flow downstream of the circular opening so that the Sonaray can obtain reliable measurements of input discharges.

\section{Software and programming}

The software used for the automatic control of the BayDrive gate is FarmConnect ${ }^{\circledR}$ by Rubicon Water, which consists of a webbased interface so that the farmer can manage the irrigation online using a computer or a smartphone. The map of the farm and the irrigation layout are displayed on a Google satellite map so that the farmer can quickly navigate to the field devices, such as the water level sensor or the bay gate, to check or modify their status (Figure 3). The GSM connection allows the field data to be uploaded to the dedicated server every $15 \mathrm{~min}$ immediately after any request. The farmer can observe in real time the field conditions and can decide to change or set the irrigation protocol according to the needs. Powerful scheduling software allows the farmer to program multiple irrigation sequences in advance. In the case of specific irrigation requirements or a change in water availability, the farmer can freely choose the watering sequence that is better suited to any crop stage, soil condition and agronomic treatment.

The FarmConnect ${ }^{\circledR}$ software acquires the measurements of the sensors or control gates with a specified frequency and stores the time series of measurements in a dedicated server. The embedded software is written in $\mathrm{C}$ code and consists of a clock and calendar schedule based on the clock time counter. The program obtains sensor readings every five minutes, but it can also be set to different frequencies by modifying the corresponding set-up variables. Each FarmConnect ${ }^{\circledR}$ unit is configured at the moment of installation to communicate with the hardware connected. For example, a FarmConnect ${ }^{\circledR}$ unit that is set up as a level sensor will poll the attached level sensor for level information and transmit these data via ZigBee radio to the FarmConnect ${ }^{\circledR}$ Gateway. There is only one FarmConnect ${ }^{\circ}$ Gateway in the network, and it is responsible for collecting data from all of the other units, communicating with the server, and managing the irrigation program. For establishing the irrigation protocols and the date and logging intervals, as well as for retrieving or erasing data from the memory, a simple menu can be accessed via the FarmConnect ${ }^{\circledR}$ web page. This menu also offers the options of reading actual sensor values and the current software settings at any time.

In this case study, the irrigation protocol settings were articulated at two levels. The first level imposes the maintenance of a minimum water level in the field $(10 \mathrm{~cm})$ to ensure that no damage would occur to the crop. In particular, in each irrigation program, it is necessary to indicate the minimum and maximum water levels required in the field to determine when to open and close the gate,
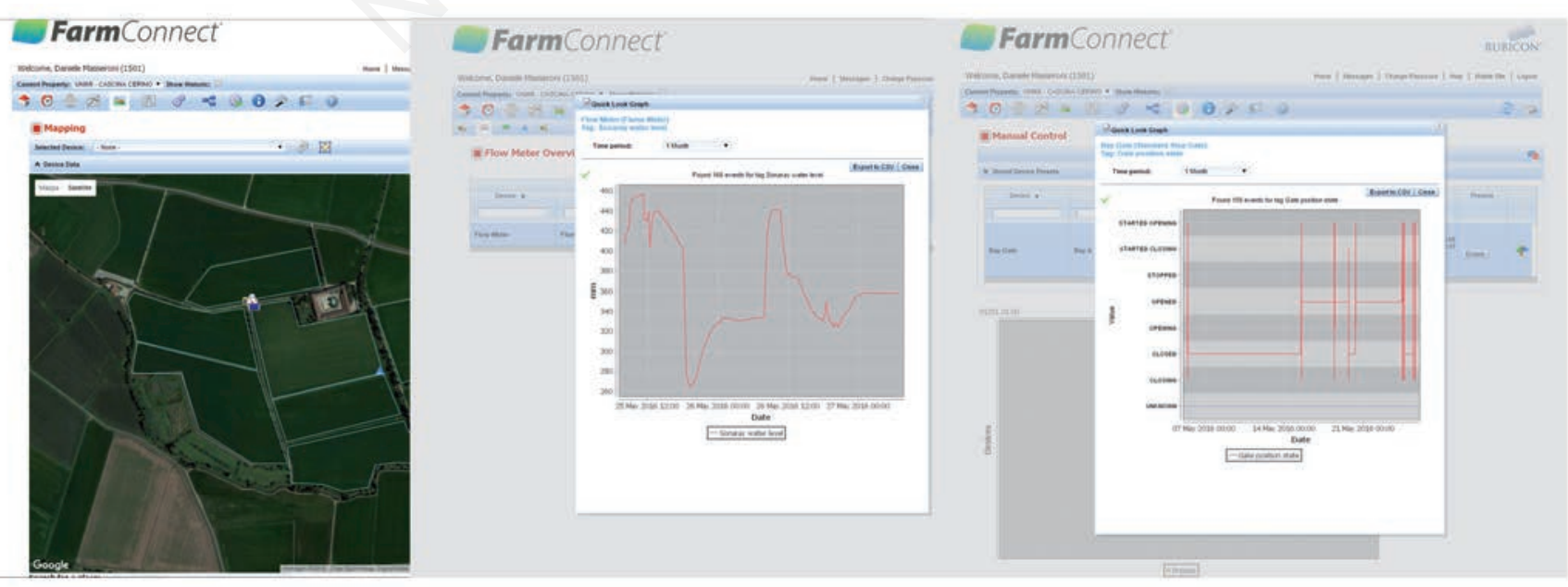

Figure 3. FarmConnect ${ }^{\circledR}$ web interface. 
respectively. The range can be a few millimetres. A control algorithm is implemented, which includes a stability function that sends the input for opening or closing the gate only if the minimum or maximum water level thresholds are exceeded for $5 \mathrm{~min}$. This criterion assures stability in the opening and closing phases of the gate to prevent the continuous activation of the regulation engine. The second level can be managed autonomously by the farmer in response to specific crop needs and based on a sub-daily timing. Finally, the farmer also maintains the option to operate the gate manually.

\section{Results and discussion}

The need for a more sustainable and integrated approach of water resources management in Southern Europe is reflected by the water-related policies and legislations. A national example can be found considering a recent Italian law (Ministerial Decree no. 213; Italian Regulation, 2015) that recognises the urgent need to enhance the knowledge of irrigation consumption and to develop systems for increasing the efficiency of deliveries and the regulation of water flows at the field and irrigation district scales, respectively. In this context, the future of any traditional gravity-fed surface irrigation systems might be uncertain because pressurised irrigation systems could be preferred by many water managers and farmers due to their simpler and faster irrigation quantification and control. However, through targeted rehabilitation measures of the gravity-fed surface irrigation systems (as shown in this work) based on gate automation, remote and feedback controls, and realtime optimisation of flows, it is possible to achieve significant improvements reaching high water use efficiency (Koech et al., 2014). Thus, using appropriate irrigation management systems based on automatic flow rate-regulation and real-time control, the gravity-fed surface irrigation systems perform with nearly the same responsiveness and efficiency as pressurised systems (Gonçalves and Pereira, 2009). The application of the BayDrive system described in this study could enable reaching the performances already achieved in other territorial contexts in which the automation and control of gravity-fed surface irrigation systems have demonstrated potential to reduce farmer labour requirements for irrigation management, increase water use efficiency, reduce runoff and ensure a greater long-term convenience for farmers (Gonçalves et al., 2011; Smith et al., 2016).

However, these approaches are not yet widely adopted in Europe, primarily due to the difficulty of integrating automatic gates into the traditional irrigation networks, the amount of investment that is not always profitable for small fields and the current low level of computerisation on EU Mediterranean farms. In this context, the idea presented in this study aims to overcome these obstacles through the development of flexible and easy-to-use automatic gates equipped with remote controlled systems and monitoring devices for an assisted and real-time management of irrigation. However, for the farmer hosting the experimentation, changing from his traditional irrigation management system to a new automatic and remote controlled system must meet three fundamental requirements: i) the automatic and remote controlled irrigation system must be equipped with robust and reliable hardware; ii) the software should be capable of mobile accessible anywhere; and iii) the system must automatically alert the farmer of any problems. Moreover, the gates must be adapted to the hydraulic features of the European rural irrigation networks characterised by small sections and flows compared with those existing in Australia or USA irrigation networks. Therefore, as this project moves forward, it is important to adopt a multi-actor approach, merging expertise from universities, farmer organisations, irrigation agencies and consortiums; their involvement would provide an added value to better understand how the FarmConnect ${ }^{\circledR}$ systems could be improved in accordance with the local requirements and the future challenges related to irrigation policies and frameworks. Additionally, transversal scientific backgrounds, from mechanical and automation engineering to agronomic competences, would be fundamental to improve and adapt the system to local requirements.

\section{Conclusions}

In this study, the characteristics of an automatic and remote controlled system for bay-drive irrigation installed during the 2016 agricultural season in a typical paddy field in northern Italy was illustrated. Hardware and software components were designed and implemented ad-hoc to guarantee the preservation of the irrigation network structures of the farm, as well as those of the traditional crop management. The installed technology is currently applied in many farms in Australia and in the USA, but this is the first time it has been tested for irrigation management of a traditional paddy rice field in Europe.

This study represents an original effort to integrate new technologies into traditional gravity-fed surface irrigation systems, aiming at the following goals: i) improving the efficient use of water through the monitoring and control of the flow discharge at the field scale; ii) preserving the historical heritage of the hydraulic network of the farm; iii) increasing the farmer's awareness of water used for irrigation; iv) decreasing the time spent by the farmer for irrigation management; v) increasing the propensity to adopt new technologies and the degree of computerisation at the farm level; and vi) increasing the competitiveness of surface irrigation systems with respect to pressurised irrigation systems, which in many parts of northern Italy, are tending to replace the old systems because of their higher irrigation efficiency and simple management.

\section{References}

BDA Group. 2007. Cost benefit analyses of research funded by the CRDC. Report to Cotton Research and Development Corporation, BDA Group, Manuka, ACT, Australia. Available from: http://www.crdc.com.au/sites/default/files/pdf/BDA\% 20FINAL\%20Hero\%20Report\%20(5-11).pdf

Cesari de Maria S., Rienzner M., Facchi A., Chiaradia E.A., Romani M., Gandolfi C. 2016. Water balance implications of switching from continuous submergence to flush irrigation in a rice-growing district. Agr. Water Manage. 171:108-19.

Chiaradia E.A., Facchi A., Gharsallah O., Romani M., Bischetti G.B., Gandolfi C. 2013. Water balance of rice plots under three different cultivation methods: first season results. Proceedings of the 10th Conference of the Italian Society of Agricultural Engineering: "Horizons in agricultural, forestry and biosystems engineering", September 8-12, Viterbo, Italy. J. Agricult. Engine. XLIV(s1):abstract.

Dassanayake D., Dassanayake K., Malano H., Dunn M., Douglas P., Langford L. 2010. Water saving through smarter irrigation 
in Australian dairy farming: use of intelligent irrigation controller and wireless sensor network. 18th World IMACS/MODSIM Congress, 13-17 July 2010, Cairns, Australia.

ERSAL (Ente regionale di sviluppo agricolo della Lombardia). 1993. I suoli della lomellina settentrionale: progetto "Carta pedologica”. ERSAL, Milano, Italy.

European Commission. 1992. Council Directive 92/43/EEC of 21 May 1992 on the conservation of natural habitats and of wild fauna and flora. In: Official Journal, L 206, 22/07/1992, pp. 7-50.

EUROSTAT. 2013. Available from: http://ec.europa.eu/ eurostat/data/database

Gillies M.H., Smith R.J. 2015. SISCO: surface irrigation calibration and optimisation. Irrig. Sci. 33:339-55.

Gillies M.H., Smith R.J., Williamson B., Shanahan M. 2010. Improving performance of bay irrigation through higher flow rates. Australian Irrigation Conference and Exhibition, 8-10 June, Sydney, Australia.

G\&M Poly Irrigation. 2013. Aquator. Cohuna, VIC, Australia. Available from: http://gmpoly.com.au/product_range/aquator Accessed: 30 March, 2013.

Goncalves J.M., Horst M.G., Pereira L.S. 2011. Furrow irrigation design with multicriteria analysis. Biosyst. Engine. 109:266-75.

Gonçalves J.M., Pereira L.S. 2009. Decision support system for surface irrigation design. J. Irrig. Drain. Eng. 135:343-56.

ISTAT. 2009. Donne della terra: i loro "numeri" per e nell'agricoltura. Atti del convegno - Roma, 13 gennaio 2006; Diffuso il: 27 aprile 2009. Available from: http://www3.istat.it/dati/catalogo/20090427_00/

Italian Regulation. 2015. Ministero delle Politiche Agricole Alimentari e Forestali - Decreto 31 luglio 2015 - Approvazione delle linee guida per la regolamentazione da parte delle Regioni delle modalità di quantificazione dei volumi idrici ad uso irriguo. (15A06988). In: (G.U. Ser. Gen., no. 213, 14/09/2015. Available from: http://www.gazzettaufficiale.it /eli/id/2015/09/14/15A06988/sg

Khatri K.L., Smith R.J. 2006. Real-time prediction of soil infiltration characteristics for the management of furrow irrigation. Irrig. Sci. 25:33-43.

Khatri K.L., Smith R.J. 2007. Toward a simple real-time control system for efficient management of furrow irrigation. Irrig. Drain. 56:463-75.

Koech R.K., Smith R.J., Gillies M.H. 2014. A real-time optimisation system for automation of furrow irrigation. Irrig. Sci. 32:319-27.

Köppen W. 1936. Das geographische System der Klimate, vol. 1,
Part C. In: W. Köppen and R. Geiger (Eds.), Handbuch der Klimatologie. Verlag von Gebrüder Borntraeger, Berlin, Germany, pp. 1-44, 4.

Leibundgut C., Kohn I. 2014. European traditional irrigation in transition part I: irrigation in times past-a historic land use practice across Europe. Irrig. Drain. 63:273-93.

LSU AgCentre. 2014. 2014 Rice Research Station annual report. Available from: http:/www.lsuagcenter.com/portals/ our_ offices/research_stations/rice/features/annual\%20report/2014rice-research-station-annual-report

Niblack M., Sanchez C.A. 2008. Automation of surface irrigation by cut-off time or cut-off distance control. Trans. ASABE 24:611-4.

Raine S.R., Bakker D.M. 1996. Increased furrow irrigation efficiency through better design and management of cane fields. Proc. Aust. Soc. Sugarcane Technol. 1996:119-24.

Russo S., Callegarin A.M. 2007. Rice production and research potential in Italy. Cahiers Opt. Méditerr. 24:139-46.

Rubicon Water. 2013. FarmConnect ${ }^{\circledR}$ Software. Fort Collins, CO, USA. Available from: http://www.rubiconwater.com/catalogue/farmconnect-software-usa Accessed: 30 March, 2013.

Schaap M.G., Leij F.J., van Genuchten M.Th. 2001. ROSETTA: A computer program for estimating soil hydraulic parameters with hierarchical pedotransfer functions J. Hydrol. 251:163-76.

Shahidian S., Serralheiro R. 2012. Development of an adaptive surface irrigation system. Irrig. Sci. 30:69-81.

Sekozawa T. 2010. A fully automated water management system for large rice paddies. Proceedings of the 14th WSEAS International Conference on Systems: part of the 14th WSEAS CSCC multiconference. World Scientific and Engineering Academy and Society (WSEAS), Stevens Point, WI, USA, $\mathrm{I}: 325-330$

Smith R.J., Gillies M.H., Shanahan M., Campbell B., Williamson B. 2009. Evaluating the performance of bay irrigation in the GMID. Irrigation Australia 2009: Irrigation \& Drainage Conference, 18-21 October, Swan Hill, Victoria, Australia.

Smith R.J., Raine S.R., Minkovich J. 2005 Irrigation application efficiency and deep drainage potential under surface irrigated cotton. Agric. Water. Manage. 71:117-30.

Smith R.J., Uddin J.M, Gillies M.H., Moller P., Clurey K. 2016. Evaluating the performance of automated bay irrigation. Irrig. Sci. [In press].

USDA (United States Department of Agriculture). 1975. Soil Taxonomy, 1st ed. Soil Survey Staff, United States Department of Agriculture, Natural Resources Conservation Serv., Washington, DC, USA. 